\title{
Labor pains in the early days of the Nobel Committee for Chemistry
}

\author{
Anders Liljas ${ }^{1}(\mathbb{D})$ \\ Received: 22 September 2016 / Accepted: 20 October 2016 / Published online: 9 November 2016 \\ (C) The Author(s) 2016. This article is published with open access at Springerlink.com
}

\begin{abstract}
Human activities have been marred for ages by conflicts of interest. This is no less true in the field of science. In the early years of the Nobel Prizes, little attention was focused on this aspect, but awareness steadily grew. In particular, this concerned Swedes nominated for Nobel Prizes, who were most likely themselves members of the Royal Swedish Academy of Sciences, but whose fellows at the Academy should treat them equally with respect to foreign nominees. In addition, conflicts of interest can arise when committee members have close contacts with nominated scientists, regardless of nationality.
\end{abstract}

Keywords Royal Academy of Sciences $\cdot$ Nobel Committee for Chemistry · Svante Arrhenius · Theodor Svedberg · Hans von Euler $\cdot$ Arne Tiselius $\cdot$ WM Stanley

\section{Introduction}

The inventor and entrepreneur Alfred Nobel died on December 10, 1896, leaving a fortune of about 30 million Swedish crowns. Less than 2 weeks earlier, he had written his final will, describing the prizes that he wanted to be awarded in his memory [1]. This was probably his best invention ever, since these prizes remain uniquely appreciated around the globe. The will described that the annual prizes in physics and chemistry should be awarded by The Royal Swedish Academy of Sciences in Stockholm. In 1897, the

Anders Liljas

anders@1iljas.net

1 Department of Biochemistry and Structural Biology, Center for Chemistry and Chemical Engineering, Lund University, Box 118, SE-221 00 Lund, Sweden
Academy did not immediately accept this offer, but some scientists, including Svante Arrhenius, were of a different opinion [2]. They managed to change the attitude of the Academy and worked out details of the nomination procedure, how the committees for the physics and chemistry prizes should be organized, and how the Academy should be engaged in the process [3].

Swedes are proud of their scientific history. Despite being a small country, scientists like Linnaeus, Scheele, and Berzelius have in the past gained lasting international reputations. Swedish scientists of international recognition would likely be members of the Academy of Sciences and may be even members of the Nobel Committees for Physics or Chemistry. Sometimes, they could receive nominations for the prize and thereby generate problems of conflicts of interest. This was not initially clearly addressed. In addition, members of the Academy at times made serious campaigns for candidates of their liking [1,3]. This article will focus on some instances where conflicts of interest arose for prizes in chemistry in the early phase of the Nobel Prizes.

\section{Svante Arrhenius}

Arrhenius (1859-1927) studied mathematics, physics, and chemistry at Uppsala University and finished his BA in 1878. During his work for a doctor's degree, he found a stronger support for his scientific interests at Stockholm University College (Högskola) and at the Royal Swedish Academy of Sciences than at Uppsala [1-3]. His research related to both physics and chemistry and focused on the electrolytic conductivity of dissolved salts. He concluded that the salts, when dissolved, dissociated into positive and negative ions that enabled the solution to conduct electric currents. This met with significant disbelief among senior scientists. Since the 
Högskola could not award doctor's degrees, he had to defend his thesis at Uppsala University. The dissertation, on May 26, 1884 , became a crucial moment for Arrhenius, since the leading professors of the faculty, Cleve and Thalén, did not appreciate his thesis and scored it too low for a continued academic career, at least in Uppsala. However, Arrhenius sent his thesis to several renowned scientists abroad and generated a stronger interest than in Uppsala. In particular, it found an enthusiastic supporter in Ostwald in Riga. Ostwald soon paid a visit to Sweden and Arrhenius to discuss further their common scientific interests. Ostwald's enthusiasm for Arrhenius' work convinced the professors at Uppsala University so that Arrhenius was given the title of "docent" (corresponding to associate professor) in the new subject of physical chemistry at the university.

In 1886, Arrhenius started a journey to get to know the leading chemists at the time. He first joined Ostwald in Riga to continue working on the conductivity of various solutions. From there, he continued to Würtzburg to work with Kohlrausch and Fischer. Next, he moved to Graz in Austria to work with Boltzmann. He returned to Stockholm Högskola in 1891 where he became professor of physics in 1895 .

Despite the fact that Arrhenius in 1898 was instrumental in developing the structure and rules for the selection of Nobel laureates, he was not elected to be a member of the Academy until 1901. The members of the Nobel committees were recommended by the physics and chemistry classes and elected by the Academy. In the nomination of prizewinners, it was essential that foreign scientists participated. Until about 1960, the reviewing process was handled solely by the committee members, but after some years, foreign scientists also became important in the reviewing process.

The physics class of the Academy suggested four members of the first Nobel Committee for Physics. The members became Thalén (Uppsala), Hasselberg as chair (The Academy, Stockholm), Ångström (Uppsala), and Hildebrandsson (Uppsala). The fifth member, Arrhenius (Stockholm University College), was elected by the whole Academy. The chemistry class proposed Cleve (Uppsala) as chair, Pettersson (Stockholm), Klason (KTH, Stockholm), and Widman (Uppsala). In this case, the whole Academy elected Söderbaum (Agricultural Academy, Stockholm) as a member of the chemistry committee.

In 1901, the first year of the Nobel Prizes, Arrhenius was nominated for the prizes in both physics and chemistry. The discussions of the physics committee focused on whether the prize in physics should be awarded to Röntgen alone or together with Lenard. Arrhenius participated in these meetings. No discussion seems to have emerged concerning the fact that he, being a committee member, was nominated. Rather, he and Ångström were asked to write the conclusions of the committee to recommend Lenard and Röntgen as the laureates in physics in 1901. On November 5, Arrhenius and
Rubensson wrote to the Academy saying that one would be enough. Subsequently, it was then decided by the Academy that Röntgen alone should be awarded the prize.

Arrhenius also became an adjunct member of the chemistry committee in 1901. van 't Hoff was nominated, by some for a shared prize with Arrhenius. Arrhenius, thus being a serious candidate, was asked by the committee to respond to the comment by critics that van 't Hoff's achievements were about 16 years old and did not really correspond to the will by Nobel, that the prize should be awarded for recent achievements. Arrhenius response was the work by van 't Hoff was theoretical and needed time for practical verifications. The result was that van ' $t$ Hoff was awarded the first Nobel Prize in chemistry.

In 1902 and 1903, Arrhenius was again proposed for the prizes in chemistry and physics and by an increasing number of nominations (Table 1). At the time, he was the only scientist nominated in both categories.

It is interesting to note that Cleve, chairperson of the chemistry committee, who was the main chemistry professor at Uppsala at the time of Arrhenius's dissertation and who had been critical to the thesis by Arrhenius nominated Arrhenius for the prize in chemistry in both 1901 and 1903.

At one of the meetings in 1902 of the physics committee, Arrhenius refrained from participating in making the recommendation to the Academy for the prize. Subsequently, in the spring of 1903, Arrhenius was unable to participate in two of the committee meetings for health reasons. In August, he

Table 1 Some repeated nominations in chemistry and physics 19011903. The figures in bold signify the laureate of that year (source: Nomination database found at nobelprize.org). The $\mathrm{C}$ or $\mathrm{P}$ preceding a year signifies nominations in chemistry and physics respectively

\begin{tabular}{llccccc}
\hline Name & C1901 & P1901 & C1902 & P1902 & C1903 & P1903 \\
\hline Arrhenius & 3 & 3 & 5 & 3 & $\mathbf{1 2}$ & 7 \\
Baeyer & & & 1 & & 2 & \\
Becquerel & 1 & & 3 & & 6 & \\
Berthelot & 1 & & 5 & & 1 & \\
M and P Curie & & & & 3 & & $\mathbf{5}$ \\
Fisher & 4 & & $\mathbf{5}$ & & & \\
Kerr & & & & 2 & & 1 \\
Lenard & & 6 & & 1 & & 1 \\
Lorentz & & & & $\mathbf{6}$ & & \\
Marconi & & 1 & & 2 & & 6 \\
$\begin{array}{l}\text { Moissan } \\
\text { Ramsay }\end{array}$ & 1 & & 1 & & 3 & \\
Lord Rayleigh & & & 3 & & 4 & \\
Röntgen & & $\mathbf{1 6}$ & & & & \\
Thompson & & 1 & & & & \\
van 't Hoff & $\mathbf{1 1}$ & & & & & \\
Zeeman & & 2 & & & & \\
\hline
\end{tabular}


wrote to the Academy that he wanted to be excused from participating in the work of the committee until December 10, 1903, the date of awarding the prizes. Likewise, he did not attend the autumn meetings of the Academy.

In April 1903, the chemistry committee focused on Arrhenius but concluded that his science concerned in equal measure physics and chemistry, with a good number of nominations for both prizes. Some members of the committee thought it would be optimal if Arrhenius was awarded half of the prize in physics and half of the prize in chemistry. The other halves could be awarded to Rayleigh and Ramsay in physics and chemistry, respectively. This won the support of three of the five members of the committee. The other two wanted to give Arrhenius a full prize in chemistry [4]. The suggestion was submitted to the physics and chemistry classes of the Academy. The former responded that the physics that Arrhenius had done could not measure with that of some of the other nominees and would therefore not qualify for a prize. At their meeting in May, the chemistry committee could not agree on whether Arrhenius alone should get the prize or whether he should share it with Ramsay [5]. In the subsequent recommendation to the Academy, the majority of the committee wanted to award Ramsey the prize for 1903 . Two of the members, Cleve and Klason, were of the opinion that Arrhenius should get the prize [6]. The chemistry class was of a different opinion and voted against the proposal by the committee with a majority of seven to three. Their recommendation was therefore that Arrhenius alone should get the prize in chemistry [7]. A delay in awarding a prize for further discussions with the physicists could signal a Swedish disinterest in the great discoveries in chemistry that Arrhenius had made. The Academy supported this recommendation and Arrhenius was awarded the prize in chemistry in 1903 [8].

\section{Theodor (The) Svedberg}

Svedberg (1884-1971) started his studies at Uppsala University in 1904 and got his BA in 1905. He defended his thesis on colloids in 1908 and became professor of physical chemistry in 1912 at Uppsala, at the age of 28. He continued to work on colloidal particles and Brownian motion. This work has not stood the test of time and was criticized by Einstein and Perrin [9]. One of several problems was that he regarded the Brownian motion as oscillatory. Subsequently, he focused on developing the ultracentrifuge for separation of particles like proteins and for determination of their molecular weights. In September 1926, he could write in his laboratory records that centrifugation studies of hemoglobin showed only one molecular weight [10]. This is regarded as a critical step in the development of molecular biology.

Svedberg was nominated for a prize in chemistry as early as 1911. In 1913, he was again nominated, now together with
Perrin in physics. In the same year, he was elected to the Academy. In 1917 and 1918, he had one nomination in chemistry each year (Table 2). In 1918, Arrhenius evaluated Svedberg's work without any conclusion about its worthiness for a prize. In 1919, Svedberg had several nominations both in physics and in chemistry, all from Swedish colleagues. Two of the nominations were for a shared prize with Perrin concerning the structure of solutions of colloids and crystalloids. Söderbaum evaluated whether a shared prize in chemistry with Perrin would be appropriate. He recommended to award both. However, other members of the committee pointed out that the prizes to von Laue and father and son Bragg were awarded for stronger evidence for the atomistic and molecular structure of nature. Söderbaum disagreed strongly.

In 1925, there was a place open in the Nobel Committee for Chemistry. The committee wanted to recruit Palmaer, the secretary of both the Nobel Committees of Chemistry and Physics, but the Academy elected Svedberg with a narrow margin. One of Svedberg's first duties in the committee was to evaluate von Euler-Chelpin (see below).

During the years 1920-1926, Svedberg got at most one nomination per year, sometimes none at all (Table 2). In 1925, Svedberg asked to be excused from contributing to the recommendation for a prize to the Academy. This year, the committee suggested that the prize in chemistry should be delayed until next year.

In 1926, Svedberg was again nominated, now together with Perrin and Tamann. He and von Euler-Chelpin (see below) wanted their nominations to be disregarded this year. The committee decided unanimously to recommend the Academy to award Zsigmondy (no nomination for 1925, but three for 1926) the prize in chemistry for 1925 for his work on colloids and to delay the prize of 1926 until next year. The records of the Nobel Committee for Chemistry contain no evaluation of the nominees of 1926 or recommendation for the prize [11].

At its meeting on November 11, 1926, the Academy decided to award Zsigmondy the prize in chemistry for 1925 . His work was related to colloids and Brownian motions. At this point, Prof. Benedicks took the floor and suggested that, since this year was the 25th anniversary of the first awarded Nobel Prizes, it would be a pity not to award the prizes for this particular year [12]. He first suggested that Perrin, who had not received much enthusiasm from the Nobel Committee for Physics, should be awarded the prize in physics. This suggestion did not immediately win the support of the Academy, but after several rounds of voting, the proposal of Prof. Benedicks won. He then continued to suggest that his friend Svedberg should be awarded the prize in chemistry. Svedberg, who was present at the meeting, then left the room. Despite the fact that Svedberg only had occasional nominations and was not recently evaluated this proposal also met with sufficient support. The Academy decided that Svedberg should be awarded the 
Table 2 Some repeated nominations in chemistry 1916-1929. The years when no prize was awarded are written in italics. The figures in bold signify the laureate of that year (source: Nomination database found at nobelprize.org)

\begin{tabular}{|c|c|c|c|c|c|c|c|c|c|c|c|c|c|c|}
\hline Name & 1916 & 1917 & 1918 & 1919 & 1920 & 1921 & 1922 & 1923 & 1924 & 1925 & 1926 & 1927 & 1928 & 1929 \\
\hline Bosch & 1 & & & & 5 & & & & & & 1 & & & 2 \\
\hline Clamician & 1 & & & 1 & & 3 & & & & & & & & \\
\hline Curtius & 5 & 1 & & 1 & & 1 & 4 & 1 & 6 & & & & & \\
\hline Eder & 1 & & & & & 9 & & & & & & & & \\
\hline Fisher & 1 & & & 1 & 1 & & & & & & & & 1 & 8 \\
\hline Guye & & 3 & 2 & 3 & 2 & 3 & 5 & & & & & & & \\
\hline Haber & 3 & & 1 & 2 & & & & & & & & & & \\
\hline Haller & & & & 5 & 1 & 1 & 1 & 1 & 1 & 7 & & & & \\
\hline Nernst & 6 & 4 & & & 8 & 22 & & & & & & & & \\
\hline Perkin & & & 1 & 3 & 2 & & & & & 1 & & & & 1 \\
\hline Perrin & & & & 2 & 1 & & 1 & 1 & 1 & 1 & 3 & & & \\
\hline Svedberg & 1 & & 1 & $4^{*}$ & 1 & & & 1 & 2 & & 1 & & & \\
\hline Sörensen & & & & & & 4 & 3 & 2 & 1 & & & & & \\
\hline Tammann & & & & & & 1 & 4 & 2 & 1 & & 4 & 2 & 5 & 1 \\
\hline Urbain & 2 & 1 & & & 2 & 2 & 4 & 3 & 4 & 3 & 9 & 3 & 3 & 2 \\
\hline von Euler-Chelpin & & & & & & & & & 2 & 2 & 3 & 3 & 2 & 4 \\
\hline Zsigmondy & & & & & & 1 & 1 & 3 & 1 & 0 & 3 & & & \\
\hline
\end{tabular}

*Nominated only by Swedish colleagues

prize in chemistry for 1926 "for his work on disperse systems" [12]. Thus, at one prize ceremony, three prizes were awarded for work related to Brownian motions.

Rumor has it that when Svedberg was waiting for the train to Uppsala, another Uppsala member of the Academy, the archbishop Nathan Söderblom caught up with him. He could inform Svedberg that he had just been awarded the prize for chemistry of 1926. The Nobel lecture by Svedberg presented in the spring of 1927 focuses entirely on the new direction of his work, the ultracentrifuges that he had constructed and that showed distinct molecular weights for proteins. His prize and activities led to significant support from the Swedish government [3]. It has been said that Svedberg had to show that he deserved the prize in retrospect.

\section{Hans von Euler-Chelpin}

von Euler-Chelpin (1873-1964) was born and went to school in Germany. Before he started his studies in science taught by Fischer, Warburg and Planck, he studied painting in Munich 1891-1893. He received his doctorate in 1895 with Fischer. He subsequently worked with Nernst in Göttingen and Arrhenius in Stockholm, also spending some time with van ' $t$ Hoff. In 1899, he was appointed to teach at the Royal Institute of Technology (KTH) in Stockholm where he became professor of general and organic chemistry in 1906. During both world wars, he served Germany in different ways with a strong affinity for German politics including Nazi sympathies [13]. His scientific interest gradually turned toward biochemistry. The Rockefeller and Knut and Alice Wallenberg foundations supported the formation of a Vitamin Institute in Stockholm in 1929, where he was appointed to be its director.

von Euler-Chelpin was elected to the Royal Academy of Sciences in 1914 and was nominated for the prize in chemistry from 1924-1929 (Table 2). In 1925, he did not want to be considered for the prize. In 1927, von Euler-Chelpin proposed that the Nobel committees should be formed at the end of January each year. When all nominations were available, the Academy could in this way avoid conflicts of interest. Both Nobel committees rejected the proposal and so did the Academy.

von Euler-Chelpin replaced Widman as a member of the Nobel Committee and served during 1929-1946. Söderbaum was now the chairperson of the committee. In March 1929, von Euler-Chelpin asked to be excused from the current year's work in the Nobel committee. The committee decided to recommend the Academy to award the prize in chemistry to von Euler-Chelpin and Arthur Harden "for their investigations on the fermentation of sugar and fermentative enzymes" [14]. The Academy decided accordingly [15].

\section{Svedberg, Tiselius and the evaluations of Sumner, Northrop, and Stanley}

Willstätter, who obtained the prize in chemistry in 1915, and was an authority in the field of biochemistry, was of the 
opinion that enzymes were entities of unknown composition [16]. However, gradually, most scientists came to believe that enzymes must be proteins, but how to get them in pure form for further analysis was not known. Experiments by Sumner became a breakthrough. He could isolate enzymes in pure and crystalline form and prove that they were indeed proteins. Northrop's contributions were less unique but showed the generality of Sumner's work.

The American biochemist Stanley purified viruses, primarily tobacco mosaic virus (TMV) and found the purified material to remain infectious [17]. This work garnered wide attention and made Stanley very well known. His early work concerned the chemical nature of TMV. Stanley's observations, partly in collaboration with Svedberg, suggested that TMV was a giant protein (with a molecular weight around $17 \mathrm{MDa}$ !) that through infections could reproduce itself [18]. Stanley also claimed to have crystallized TMV [16]. The composition of the virus led to a conflict with Bawden and Pirie [19]. These British scientists showed that the virus also contained RNA. Gradually, Stanley also found a small percentage of nucleic acid in the virus, but in his publications, he avoided referring to the earlier discovery by Bawden and Pirie. Furthermore, the British scientists did not agree on the crystalline nature of Stanley's preparations. They concluded that the material could best be described as fibers. In fact, the virus has still not been crystallized. Despite the initial excitement about Stanley's work, it has in retrospect met with significant criticism [20].

Northrop, Stanley, and Sumner received many nominations for the prizes in chemistry and physiology or medicine alone or together (Table 3). Members of the Nobel Committee for Chemistry also nominated different constellations of these scientists. In 1939, Svedberg nominated Bawden, Pirie, and Stanley. In 1946, he and Tiselius nominated Northrop and Sumner, and von Euler-Cheplin nominated Sumner and Stanley.

Svedberg evaluated Stanley in 1938, 1939, and 1945 with positive conclusions [21-23]. According to present standards, this would be unsuitable, since Svedberg had collaborated with Stanley [18]. Furthermore, Svedberg obtained grants from the Rockefeller Foundation, while Stanley was working at Rockefeller University. In 1946, Tiselius was asked by the chemistry committee to serve as an adjunct member and to evaluate Sumner, Northrop, and Stanley. His report is positive to awarding Sumner and Northrop the prize, but he was not convinced that the work of Stanley was of sufficient quality. He thought that it would be impossible to reward Stanley without including Bawden and Pirie. Thus, Sumner and Northrop could be awarded but Stanley should wait [24].

At the September meeting of the committee in 1946, Tiselius' hesitation concerning Stanley changed [25]. Maybe his senior colleagues Svedberg and von Euler-Chelpin, being Nobel laureates, full members of the committee and having nominated or reviewed Stanley positively, convinced him. Furthermore, Bawden and Pirie had no current nominations and Stanley was the most active in the field. Bawden and Pirie had observed that under certain conditions, the giant virus occurred as smaller entities. Stanley criticized this observation as an artifact due to the method of preparation. The result was that the committee recommended that Sumner should receive half the prize, and that Northrop and Stanley should share the second half [25]. This was also the recommendation by the chemistry class [26], which was finally decided by the Academy [26].

\section{Arne Tiselius}

Tiselius (1902-1971) grew up in Stockholm and went to school in Gothenburg. He began his university studies in Uppsala. After having finished a bachelor's degree, he got a job in The Svedberg's department. Molecules from living species were attracting increasing attention and methods to separate them were high on the agenda. Electrophoresis was attempted and, despite the failures of others, Tiselius had great success. He finished his doctoral thesis in 1930 and obtained a
Table 3 Some repeated nominations in chemistry 1938 1948. The years when no prize was awarded are written in italics. The figures in bold signify the laureate of that year (source: Nomination database found at nobelprize.org)

\begin{tabular}{|c|c|c|c|c|c|c|c|c|c|c|c|}
\hline Name & 1938 & 1939 & 1940 & 1941 & 1942 & 1943 & 1944 & 1945 & 1946 & 1947 & 1948 \\
\hline Bawden & & 1 & & & & & & & & & \\
\hline Hahn & & & & 2 & 2 & 1 & 1 & 1 & 1 & & \\
\hline de Hevesy & & 4 & 3 & & 1 & 1 & 2 & & & & \\
\hline Northrop & & & 1 & 7 & 1 & 1 & 2 & 3 & 2 & & \\
\hline Pauling & & & 2 & 1 & & 1 & 3 & & 3 & & 17 \\
\hline Pirie & & 1 & & & & & & & & & \\
\hline Robinson & 5 & 2 & 7 & 1 & 4 & 2 & 6 & 2 & 5 & 5 & \\
\hline Stanley & 1 & 2 & & 1 & 1 & 2 & 2 & 2 & 2 & & \\
\hline Sumner & & & & 3 & & & 1 & 1 & 3 & & \\
\hline Tiselius & & & & & & & & & & 1 & 5 \\
\hline Virtanen & 1 & 1 & & 2 & 1 & 1 & 1 & 6 & & & \\
\hline
\end{tabular}


research professorship in biochemistry in 1938. Tiselius could show that blood serum contained four main components: albumin, $\alpha-, \beta$-, and $\gamma$-globulins. Tiselius was elected to the Academy in 1939. He was a member of the Nobel Committee for Chemistry from 1947-1971 and was nominated for prizes twelve times, six for chemistry and six for physiology or medicine. His first nomination was in 1940. In 1947, he requested not to be considered. In 1948, he received five nominations for chemistry and three for physiology or medicine. Due to the nominations of Tiselius, Hammarsten replaced him in the committee. The committee recommended him to the Academy for the prize at their meeting on September 1, 1948, and the Academy decided to award Tiselius the prize in chemistry for 1948 at their meeting on November 4.

\section{Summary}

Obviously, when the first Nobel prizes were awarded, the work of the committees was still being developed. The problem of conflict of interest was not always foreseen. Svante Arrhenius was nominated for the prize both in chemistry and in physics during the first 3 years of the Nobel Prize. Nevertheless, he worked for the Nobel Committee for Physics and assisted the Nobel Committee for Chemistry in 1901. In 1903, the year he received the prize in chemistry, he excused himself from working with the prizes from August 1903 until the day of the prize ceremony.

In the first year, The Svedberg served on the committee for chemistry, 1925, he was not nominated. In 1926, he had one nomination but requested that this nomination should be disregarded. The nomination was not reviewed, but in an entirely unique way, he was nevertheless awarded the prize for chemistry in 1926.

Hans von Euler-Cheplin (C1929) was very much aware of the problem of conflict of interest in the work with the prizes. The suggestion to elect the committee members only after the nominations were available did not win support. This proposal could make the continuity of the work severely disrupted. A better way would be to handle the problems individually when they occurred. This has generally become the guiding principle.

The circumstances of Wendell Stanley (C1946) at the Rockefeller Institute were different. In this case, Svedberg and Tiselius had directly or indirectly collaborated with him. In addition, Svedberg obtained economic support from the Rockefeller Foundation [21, 22, 27, 28]. The same group may have obtained the prize even without the contributions by Svedberg and Tiselius, but this case illustrates the difficulty with a small committee covering a wide area of research. The only real experts in the relevant area may have strong connections with the candidates for the prize.
Finally, in this brief account, the prize to Arne Tiselius was, compared to the previously described cases, simple and straightforward.

The first half century of the Nobel Prizes cannot easily be compared to the situation now. Science has grown tremendously everywhere and so has the number of nominations. A large number of institutions and individuals are invited to nominate, and the number of nominations can be around 400 annually for each prize. The committees still work along the same lines but generally, several adjunct members participate. The biggest difference is the usage of many international reviewers. Sometimes, about twenty fellow scientists can review a field or a scientist. However, the concluding reviews are always written by committee members followed by the summary by the whole committee to be reviewed by the chemistry or physics sections of the Academy leading to the final proposal for the whole Academy to decide on. These developments have made problems of conflicts of interest in identification of Nobel Prize winners much less.

Acknowledgments This brief account would have been impossible to write without the kind help and advice from Maria Asp-Dahlbäck and Prof. Karl Grandin, Center for the History of Science at the Royal Swedish Academy of Sciences, Stockholm. Dr. Derek Logan, Lund University and Prof. Istvan Hargittai, Budapest University of Technology and Economics have made kind suggestions for improvements of the text.

Open Access This article is distributed under the terms of the Creative Commons Attribution 4.0 International License (http:// creativecommons.org/licenses/by/4.0/), which permits unrestricted use, distribution, and reproduction in any medium, provided you give appropriate credit to the original author(s) and the source, provide a link to the Creative Commons license, and indicate if changes were made.

\section{References}

1. Crawford E (1984) The beginnings of the Nobel institutions. Cambridge University Press

2. Crawford E. (1996) Arrhenius. From ionic theory to the greenhouse effect. Uppsala studies in history of science, Vol. 23. Watson Publishing International.

3. Friedman RM. (2001) The politics of excellence. Behind the Nobel Prize in science. Times books, Henry Holt and Company LLC.

4. Minutes of the meeting of the Nobel Committee for Chemistry, Royal Swedish Academy of Sciences April 5, 1903.

5. Minutes of the meeting of the Nobel Committee for Chemistry, Royal Swedish Academy of Sciences May 20, 1903.

6. Committee report, Nobel committee for Chemistry. 1903.

7. Royal Swedish Academy of Sciences. Class for Chemistry. Protocol of October 31, 1903.

8. Minutes of meetings of the Royal Swedish Academy of Sciences for discussion of matters concerning the Nobel Foundation, November 12, 1903.

9. Kerker M (1976) The Svedberg and the reality of molecules. Colloid and Interface Science 5:309-320

10. Pedersen KO (1983) The Svedberg and Arne Tiselius. The early development of modern protein chemistry at Uppsala. In topics in 
the history of biochemistry. Personal recollections. Comprehensive Biochemistry 35:233-281

11. Royal Swedish Academy of Sciences. Class for Chemistry. Protocol of June 5, 1926.

12. Minutes of meetings of the Royal Swedish Academy of Sciences for discussion of matters concerning the Nobel Foundation, November 11, 1926.

13. Hargittai I (2002) The road to Stockholm: Nobel prizes, science, and scientists. Oxford University Press

14. Royal Swedish Academy of Sciences. Class for Chemistry. Protocol of September 20, 1929.

15. Minutes of meetings of the Royal Swedish Academy of Sciences for discussion of matters concerning the Nobel Foundation, November 12, 1929.

16. Willstätter R (1927) Faraday lecture. Problems and methods in enzyme research. J Chem Soc 1927:1359-1381

17. Stanley WM (1935) Isolation of a crystalline protein possessing the properties of tobacco mosaic virus. Science 81:644-645

18. Eriksson-Quensel I-B, Svedberg T (1936) Sedimentation and electrophoresis of the tobacco mosaic virus protein. J Amer Chem Soc 58:1863-1867

19. Bawden FC, Pirie NW (1937) The isolation and properties of liquid crystalline substances from solanaceous plants infected with three strains of tobacco mosaic virus. Proc Roy Soc London B123:274 320

20. Kay LE (1986) WM Stanley's crystallization of the tobacco mosaic virus, 1930-1940. Isis 77:450-472

21. Svedberg T. (1945) Special report to the Nobel Committee for Chemistry on Stanley April 20, 1945. Nobel Archive, Stockholm.

22. Norrby E (2010) Nobel prizes and life sciences. World Scientific Publishing Co.

23. Olovsson I, Liljas A, Lidin S (2014) From a grain of salt to the ribosome. World Scientific Publishing Co, The history of crystallography as seen through the lens of the Nobel Prize

24. Tiselius A (1946) Special report to the Nobel Committee for Chemistry on Northrop, Stanley and Sumner. In: September 4, 1946. Stockholm, Nobel Archive

25. Minutes of the meeting of the Nobel Committee for Chemistry, Royal Swedish Academy of Sciences September 23, 1946.

26. Royal Swedish Academy of Sciences. Class for Chemistry. Protocol of October 28, 1946

27. Minutes of meetings of the Royal Swedish Academy of Sciences for discussion of matters concerning the Nobel Foundation, November 14, 1946.

28. Pennazio S, Roggero P (2000) The discovery of the chemical nature of tobacco mosaic virus. Rivista di Biologica/ Biology Forum 93: 253-282 